Article

\title{
Activated Carbon Microsphere from Sodium Lignosulfonate for Cr(VI) Adsorption Evaluation in Wastewater Treatment
}

\author{
Keyan Yang ${ }^{1}$, Jingchen Xing ${ }^{1}$, Pingping $X u^{1}{ }^{1}$, Jianmin Chang ${ }^{1, *}$, Qingfa Zhang ${ }^{2}$ and \\ Khan Muhammad Usman ${ }^{3}$ \\ 1 College of Material Science and Technology, Beijing Forestry University, 35 Qinghua East Road, \\ Haidian District, Beijing 100083, China; ykysdut@163.com (K.Y.); jingchenx612@163.com (J.X.); \\ m18813102213@163.com (P.X.) \\ 2 School of Agricultural and Food Engineering, Shandong University of Technology, 266 Xincun West Road, \\ Zibo 255000, China; zhangqingfacll@126.com \\ 3 Department of Biological Systems Engineering, Washington State University, Richland, WA 99354, USA; \\ muhammadusman.khan@wsu.edu \\ * Correspondence: cjianmin@bjfu.edu.cn; Tel.: +86-010-6233-7733
}

Received: 19 December 2019; Accepted: 15 January 2020; Published: 19 January 2020

\begin{abstract}
In this study, activated carbon microsphere (SLACM) was prepared from powdered sodium lignosulfonate (SL) and polystyrene by the Mannich reaction and $\mathrm{ZnCl}_{2}$ activation, which can be used to remove $\mathrm{Cr}(\mathrm{VI})$ from the aqueous solution without adding any binder. The SLACM was characterized and the batch experiments were conducted under different initial $\mathrm{pH}$ values, initial concentrations, contact time durations and temperatures to investigate the adsorption performance of $\mathrm{Cr}(\mathrm{VI})$ onto SLACM. The results indicated that the SLACM surface area and average pore size were $769.37 \mathrm{~m}^{2} / \mathrm{g}$ and $2.46 \mathrm{~nm}$ (the mesoporous material), respectively. It was found that the reduced initial $\mathrm{pH}$ value, the increased temperature and initial $\mathrm{Cr}(\mathrm{VI})$ concentration were beneficial to $\mathrm{Cr}(\mathrm{VI})$ adsorption. The maximum adsorption capacity of $\mathrm{Cr}(\mathrm{VI})$ on SLACM was $227.7 \mathrm{mg} / \mathrm{g}$ at an initial $\mathrm{pH}$ value of 2 and the temperature of $40^{\circ} \mathrm{C}$. The adsorption of SLACM for $\mathrm{Cr}(\mathrm{VI})$ mainly occurred during the initial stages of the adsorption process. The adsorption kinetic and isotherm experimental data were thoroughly described by Elovich and Langmuir models, respectively. SL could be considered as a potential raw material for the production of activated carbon, which had a considerable potential for the $\mathrm{Cr}(\mathrm{VI})$ removal from wastewater.
\end{abstract}

Keywords: activated carbon microsphere; sodium lignosulfonate; $\mathrm{Cr}(\mathrm{VI})$; adsorption

\section{Introduction}

Water pollution has become a global issue because of its increasing impact on human and animal health. The presence of heavy metals in industrial water is not only causing severe damage to human and animal health, but it is also damaging aquatic life [1-3]. The effluents from a variety of industrial processes such as metallurgy, petroleum refining, batteries, and electroplating are responsible for introducing these heavy metals into aquatic environments [4,5]. These heavy metals include chromium $(\mathrm{Cr})$, cadmium $(\mathrm{Cd})$, lead $(\mathrm{Pb})$, mercury $(\mathrm{Hg})$, and other heavy metal ions and compounds [6-8]. These heavy metals are insistent and non-degradable in nature, but they are soluble in the aquatic environment; therefore, they can be easily absorbed into living cells [9]. At the same time, contamination of water by heavy metals is also considered one of the main reasons for the non-availability of potable water in developing and underdeveloped countries [10]. Among all of the heavy metals, $\mathrm{Cr}$ is one of the main 16 toxic metals considered detrimental for human health [11]. $\mathrm{Cr}(\mathrm{III})$ is a human micronutrient, 
while $\mathrm{Cr}(\mathrm{VI})$ is extremely toxic and is a strong oxidizing agent [12]. The presence of $\mathrm{Cr}(\mathrm{VI})$ in water can cause severe diseases, such as kidney circulation, dermatitis and lung cancer $[13,14]$. Therefore, removal of $\mathrm{Cr}(\mathrm{VI})$ from aquatic environments is indispensable for public health, as well as for the protection of the environment and aquatic life. Moreover, strict environmental mechanisms and the enactment of legal standards is necessary to avoid excessive discharge of $\mathrm{Cr}(\mathrm{VI})$ into potable water sources [15]. The Environmental Protection Agency (EPA) has recommended that the maximum concentration of $\mathrm{Cr}(\mathrm{VI})$ in drinking water not exceed more than $0.05 \mathrm{mg} / \mathrm{L}$ [12].

Many techniques, such as adsorption, membrane filtration, electrodialysis ion exchange, reduction, reverse osmosis and biological removal have been developed to remove $\mathrm{Cr}(\mathrm{VI})$ from aquatic environments $[13,16,17]$. Among them, adsorption is one of the most effective methods and is suitable for use in developing countries by using adsorbents [18]. Adsorption is a green and low-cost wastewater treatment technique, especially useful for heavy metal ions and hydrophilic compounds such as chromium, lead, ammonium ions and antibiotics [10,19-21]. The adsorbent generally has an abundant pore structure, while simultaneously having chemical functional groups on the surface, and it can be easily modified through increased surface charge [18]. In terms of removing chromium ions from wastewater, the adsorbent used by the adsorption method has a lower cost than the ionic exchange resins used by membrane filtration and the membranes used by electrodialysis ion exchange; furthermore, adsorption is easier to perform than reduction and reverse osmosis, and it has a higher processing efficiency and more extensive application fields than biological removal. In general, compared to other methods, activated carbon absorption has been proved to be a preferable technique for the removal of $\mathrm{Cr}(\mathrm{VI})$ from wastewater due to its higher efficiency, lower operating cost, higher adsorption capacity, easier operation, and non-hazardous technique. Thus, the activated carbon adsorption process has been developed and applied extensively [21,22].

Currently, the raw material to produce activated carbon comes from conventional fossil fuels such as coal and petroleum. With the development of renewable energy sources, the exploration of novel and effective adsorbents based on renewable sources has also received more attention than ever before due to the growing concerns about environment and increasing cost of fossil fuels [23]. Keeping in mind the environmental and industrialization concerns, it is necessary to develop activated carbons from low-cost and abundant precursors. During the last few years, many researchers have used adsorbents made of different types of renewable biomasses such as tobacco stems [24], longan seed [4], rice straw [25], juniperus procera sawdust, avocado kernel seeds and papaya peels [26], activated carbon derived from leucaena leucocephala [27], and sterculia guttata shell [28], and the results of these studies indicates that these adsorbents are helpful in achieving sufficient removal of $\mathrm{Cr}(\mathrm{VI})$ from wastewater. However, the cost of these adsorbents was found to be higher, due to which these adsorbents are not being used at commercial scale.

Therefore, a novel, cost-effective and efficient activated carbon is highly needed for proper and cost-effective treatment of wastewater at larger scales. The SL is an inevitable by-product of the paper and pulp industry. Currently, most of the SL generated by the paper and pulp industry is burnt or dumped into open lands and drains, which is not only causing an increase environmental pollution, but also wastes a valuable resource. It is necessary to achieve high-value utilization of SL, rather than wasting it. In addition to high carbon content, SL contains oxygenic functional groups such as carboxyl and phenol hydroxyl [29]. Moreover, some researchers have also found that SL and its derivatives have remarkable electrochemical performance and the potential to adsorb certain heavy metals, including toluene, and some other pollutants [30,31]. However, the problem associated with SL as an adsorbent is its high solubility in water, due to which it is difficult to remove powder SL from aqueous solution after the adsorption process, which can cause secondary pollution. That is a common reason for limiting powder SL application as adsorbing material. To solve the separation problem of powder SL after adsorption from solution, magnetic lignosulfonate was fabricated based on magnetic separation technique [32]. However, beyond that, changing the macroscopic character of SL from powder to granular to prepare granular activated carbon is a valuable research direction for solving 
the separation problem, as well as for improving the adsorption properties of SL. The activated carbon prepared by conventional methods from SL is also powdered. However, the powdered activated carbon is very difficult to apply in wastewater treatment, because it is dispersed in the water and very hard to separate after adsorption. If the powdered activated carbon is to be applied commercially, then it must be prepared into granular activated carbon by means of a binder. However, the application of binder is costly and environmentally unfriendly. Therefore, a new preparation method for activated carbon microspheres from SL needs to be developed. Because the SL has good reaction activity, it could be used to react with basis materials such as polystyrene to generate large particles of adsorption material with easy recovery and separation, in order to realize high-value industrial utilization of SL as an adsorption material. The SL also has lower cost than many other fossil fuels as a kind of renewable biomass resource with vast reserves. Therefore, the SL that is considered to be waste in the paper and pulp industry and is generally dumped into the open environment, causing an increase in environmental pollution, can be used as a renewable precursor to substitute traditional fossil fuels for the production of activated carbon, which can then be used as a low-cost adsorbent for the removal of heavy metals from polluted aquatic environments.

Keeping in mind the acute need for low-cost and efficient renewable adsorbents in the wastewater treatment sector and the promising behavior of adsorbents prepared from biomass, in this study the SLACM was developed, aiming to remove $\mathrm{Cr}(\mathrm{VI})$ from wastewater. The preparation of SLACM was done in two steps, i.e., the preparation of activated carbon precursor from powdered SL and polystyrene by Mannich reaction without the addition of any binder, and the $\mathrm{ZnCl}_{2}$ activation of the precursor. The effects of the adsorption process on the adsorption capacity of SLACM for $\mathrm{Cr}(\mathrm{VI})$ were investigated according to batch experiments carried out under different initial $\mathrm{pH}$, initial concentration, contact time, and temperature. The prepared SLACM was characterized with respect to its pore volume, surface area, and sorption efficiency, and the transformation of structure and properties before and after $\mathrm{Cr}(\mathrm{VI})$ adsorption was compared. On the basis of the ability to remove $\mathrm{Cr}(\mathrm{VI})$ in the solution experiments, adsorption kinetics, and isotherm fitting, the potential of using SLACM for the purification of wastewater was evaluated.

\section{Materials and Methods}

\subsection{Materials}

The SL was purchased from Shanghai Macklin Biochemical Co., Ltd., Shanghai, China. The SL was composed of $41.63 \%$ carbon, $28.32 \%$ oxygen, and $24.39 \%$ sodium, as well as small amounts of silicon. The chloromethylated polystyrene was used as the base material in the preparation. chloromethylstyrene-divinylbenzene-styrene copolymer (CMPS) was purchased from Tianjin Xingnan macromolecule technology Co., Ltd., Tianjin, China. 1,3-diaminopropane $\left(\mathrm{C}_{3} \mathrm{H}_{10} \mathrm{~N}_{2}\right.$, MW 74.13) was purchased from Shanghai Macklin Biochemical Co., Ltd. Tetrahydrofuran $\left(\mathrm{C}_{4} \mathrm{H}_{8} \mathrm{O}\right)$ was purchased from Beijing Chemical Co., Ltd. Beijing, China. Formaldehyde (HCHO) was purchased from Xilong Scientific Co., Ltd., Guangdong, China. $\mathrm{ZnCl}_{2}$ was purchased from Shanghai Macklin Biochemical Co., Ltd., Shanghai, China. Methyl orange was purchased from shanghai D\&B biological science and technology Co., Ltd., Shanghai, China. Deionized water was used for all the experiments. All chemicals and materials were of analytical grade and were used without further purification.

\subsection{Preparation of SLACM}

The preparation of SLACM was done in two main steps, i.e., preparation of activated carbon precursor from powdered SL and polystyrene by Mannich reaction and the $\mathrm{ZnCl}_{2}$ activation of the precursor. The preparation process diagram of SLACM was shown in Figure 1. The substrate material CMPS need to be amination pretreated before reaction. The CMPS was first swollen $2 \mathrm{~h}$ with tetrahydrofuran $(3 \mathrm{~mL} / \mathrm{g})$ and then amination treated for $12 \mathrm{~h}$ in the $50{ }^{\circ} \mathrm{C}$ with 1,3-diaminopropane $(5 \mathrm{~mL} / \mathrm{g})$. After that, the SL and amino CMPS ware generate large particles of adsorbent resin 
microsphere (ARM) by Mannich reaction in solution catalyzed by formaldehyde at a mass ratio of 1:1. The Mannich reaction of SL and amino CMPS continuously proceed for $12 \mathrm{~h}$ in the $90^{\circ} \mathrm{C}$ water bath. The ARM samples are shown in Figure 2a. The ARM was oxidized for $30 \mathrm{~min}$ at $180^{\circ} \mathrm{C}$ before the impregnation process to obtain pre-oxidized adsorbent resin microsphere (PARM) as an activated carbon precursor. A suitable amount of PARM was added to the activator aqueous solution (50 wt.\%), and the solution was stirred continuously at room temperature to prepare a uniform solution. $\mathrm{ZnCl}_{2}$ was used as an activating agent during the impregnation process with an impregnation ratio of 1:1 of activated carbon precursors to activator respectively. After $12 \mathrm{~h}$ of the impregnation process, the samples were dried at $105^{\circ} \mathrm{C}$ for $6 \mathrm{~h}$ in an oven. The impregnated activated carbon precursors were put into a porcelain boat in a horizontal tube furnace and heated with nitrogen $(99.99 \%)$ protected. During the activation process, the temperature was initially increased from room temperature to the activation temperature of $600^{\circ} \mathrm{C}$ by using a heating rate of $10^{\circ} \mathrm{C} / \mathrm{min}$, and then the temperature was kept constant at $600{ }^{\circ} \mathrm{C}$ for $2 \mathrm{~h}$. After this, the samples were cooled to room temperature under nitrogen atmosphere. Finally, the samples were washed $2-3$ times with rare hydrochloric acid $(0.5 \mathrm{~mol} / \mathrm{L})$ and deionized water in sequence until the $\mathrm{pH}$ of filtrate became neutral and then dried at $105^{\circ} \mathrm{C}$ for $12 \mathrm{~h}$ to obtain dry SLACM. The SLACM samples are shown in Figure $2 b$.

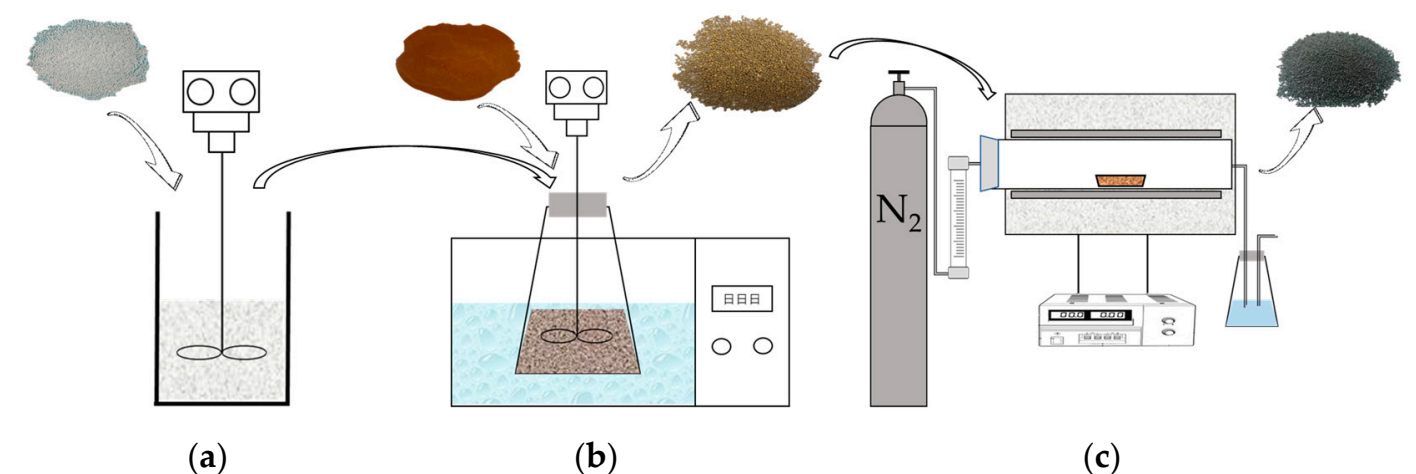

Figure 1. The preparation process diagram of SLACM: (a) Amination of CMPS; (b) Mannich reaction of SL and ACMPS; (c) Activation processes.

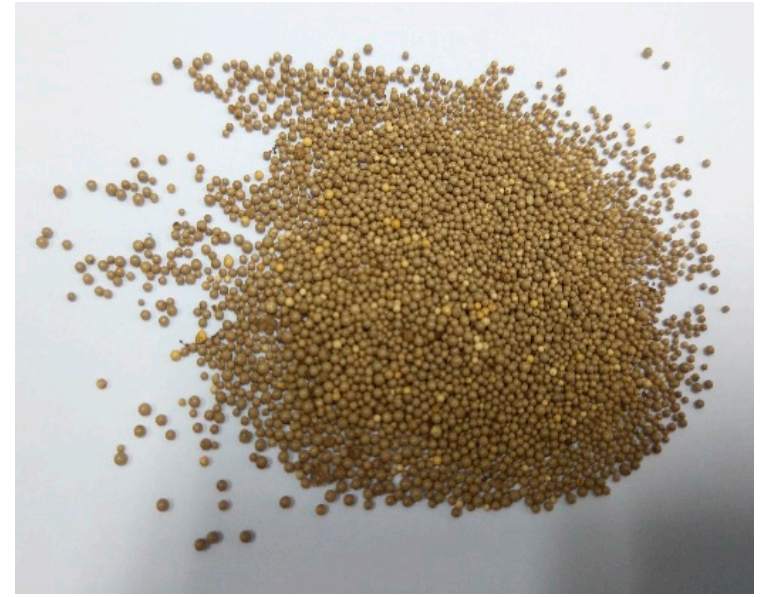

(a)

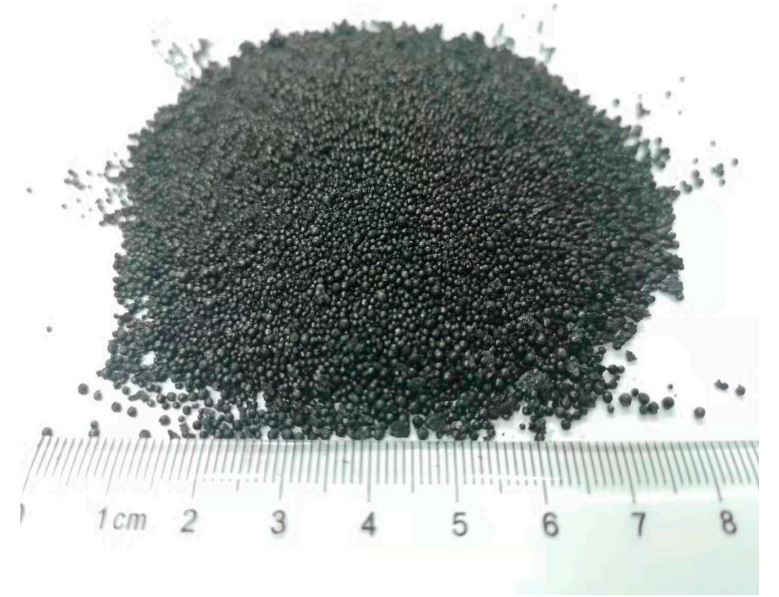

(b)

Figure 2. (a) The ARM sample picture; (b) The SLACM sample picture.

\subsection{Characterizations of SLACM}

The surface morphology of SLACM samples was observed by scanning electron microscopy (SEM, Hitachi S-4800, Hitachi, Japan) at an accelerating voltage $5.00 \mathrm{kV}$ and the element chemistry configuration was analyzed by SEM with energy dispersive spectrometry (EDS) system. 
The microstructures of the SLACM samples was characterized by transmission electron microscope (TEM, FEI TF30, Hillsboro, OR, USA). A physisorption analyzer (Quantachrome autosorb-IQ, Boynton Beach, FL, USA) was used to determine the specific surface area, pore volume and other pore characteristics of SLACM samples. The SLACM samples pulverized to carbon powder were treated by vacuum degassing $3 \mathrm{~h}$ at $200^{\circ} \mathrm{C}$ at first, and then $\mathrm{N}_{2}$ adsorption and desorption isotherms were measured at $77 \mathrm{~K}$. The specific surface area and pore volume of SLACM samples were analyzed by the BET method according to the $\mathrm{N}_{2}$ adsorption and desorption isotherms. The BET equation was applied to $\mathrm{N}_{2}$ adsorption data from $0.06<\mathrm{P} / \mathrm{P}_{0}<0.25$ to determine surface area and total pore volume was measured at $\mathrm{P} / \mathrm{P}_{0}=0.985$. The surface functional groups of SLACM were characterized before and after adsorption by using a Fourier transform infrared spectrometer (FT-IR, Thermo Scientific Nicolet iS10, San Jose, CA, USA) in the range from 4000 to $400 \mathrm{~cm}^{-1}$ at $4 \mathrm{~cm}^{-1}$ resolutions with 64 scans. The crystalline structure of SLACM specimen was investigated by X-ray diffraction (XRD, Bruker D8 ADVANCE diffractometer) with $\mathrm{Cu} \mathrm{K} \alpha$ radiation $(\lambda=0.15417 \mathrm{~nm})$ in the range of $2 \theta=10-90$ at a step rate of 0.02 . The mass change of activated carbon precursors was measured by the thermogravimetric analysis (TG) (STA449C, Selb, Germany) under an $\mathrm{N}_{2}$ atmosphere from 30 to $800{ }^{\circ} \mathrm{C}$ at the rate of $10^{\circ} \mathrm{C} / \mathrm{min}$.

\subsection{Adsorption Experiment}

All batch experiments were carried out in $250 \mathrm{~mL}$ Erlenmeyer flasks with $100 \mathrm{mg}$ SLACM and $50 \mathrm{~mL} \mathrm{Cr}(\mathrm{VI})$ solution in order to study the adsorption capacity of adsorbent on $\mathrm{Cr}(\mathrm{VI})$. Several experimental parameters which may affect the absorption efficiency of SLACM were studied, including initial $\mathrm{pH}$, contact time, temperature and initial concentration of $\mathrm{Cr}(\mathrm{VI})$. When the SLACM and $\mathrm{Cr}(\mathrm{VI})$ solution was taken in the flasks, $\mathrm{HCl}$ solution $(0.1 \mathrm{~mol} / \mathrm{L})$ and $\mathrm{NaOH}$ solution $(0.1 \mathrm{~mol} / \mathrm{L})$ was used to adjusted the initial $\mathrm{pH}$ of the solution to setting value. The Erlenmeyer flasks were then placed on a 150-rpm shaking table to determine the adsorption capacity of SLACM according to setting different contact time and temperature. After the designated time of adsorption, the mixture was separated using a $0.45 \mu \mathrm{m}$ filter. The filtrate absorbance was measured by UV-Vis spectrophotometer, and $\mathrm{Cr}(\mathrm{VI})$ concentration was calculated according to the diphenyl carbohydrazide spectrophotometric method (Chinese National Standards GB/T 7467-87). All the adsorption experiments were repeated 3 times and the average values were used as final results.

The adsorption capacity $q_{t}$ and $q_{e}$ of $\mathrm{Cr}(\mathrm{VI})$ onto SLACM were calculated as follows:

$$
\begin{aligned}
& q_{t}=\frac{\left(C_{i}-C_{t}\right) V}{M}, \\
& q_{e}=\frac{\left(C_{i}-C_{e}\right) V}{M},
\end{aligned}
$$

where $q_{t}(\mathrm{mg} / \mathrm{g})$ is the adsorption capacity at time $\mathrm{t}, q_{e}(\mathrm{mg} / \mathrm{g})$ is the adsorption capacity at equilibrium, $C_{i}(\mathrm{mg} / \mathrm{L})$ is the initial concentration of $\mathrm{Cr}(\mathrm{VI}), C_{t}(\mathrm{mg} / \mathrm{L})$ is the concentration of $\operatorname{Cr}(\mathrm{VI})$ at time $\mathrm{t}$, $C_{e}(\mathrm{mg} / \mathrm{L})$ is the concentration of $\mathrm{Cr}(\mathrm{VI})$ at equilibrium, $V(\mathrm{~L})$ is the volume of suspension of $\mathrm{Cr}(\mathrm{VI}), M$ (g) is the dry weight of the SLACM.

\subsubsection{Effects of Initial $\mathrm{pH}$ on Adsorption}

The effects of initial $\mathrm{pH}$ on the $\mathrm{Cr}(\mathrm{VI})$ adsorption were studied by adding SLACM to flasks with $150 \mathrm{mg} / \mathrm{L} \mathrm{Cr}(\mathrm{VI})$ solution under the similar experimental conditions. The $\mathrm{pH}$ value of the solution was then adjusted to $1.0,2.0,3.0,4.0,5.0,6.0,7.0,8.0$ and 9.0 by using $\mathrm{HCl}$ solution $(0.1 \mathrm{~mol} / \mathrm{L})$ and $\mathrm{NaOH}$ solution $(0.1 \mathrm{~mol} / \mathrm{L})$. All the samples were shaken in a shaking table for $12 \mathrm{~h}\left(30^{\circ} \mathrm{C}, 150 \mathrm{rpm}\right)$. 


\subsubsection{Adsorption Kinetics}

The adsorption kinetics of $\mathrm{Cr}(\mathrm{VI})$ on the SLACM was studied by using a contact times ranging from $2 \mathrm{~min}$ to $24 \mathrm{~h}$ with initial $\mathrm{Cr}(\mathrm{VI})$ concentration of $150 \mathrm{mg} / \mathrm{L}$ and $\mathrm{pH}$ value 2 . The agitation speed and the contact temperature of the shaking table were kept constant at $150 \mathrm{rpm}$ and $30^{\circ} \mathrm{C}$, respectively.

\subsubsection{Adsorption Isotherm}

Adsorption isotherms are usually used to describe the distribution of metal ions between the liquid phase and the solid phase [33]. Adsorption isotherms were performed for 20,30 and $40{ }^{\circ} \mathrm{C}$ by using initial $\mathrm{Cr}(\mathrm{VI})$ concentrations, $\mathrm{pH}$, contact time, and a shaking speed of 100 to $600 \mathrm{mg} / \mathrm{L}, 2$, 12 hand $150 \mathrm{rpm}$, respectively.

\section{Results and Discussion}

\subsection{Characterization}

The pore structure of activated carbon is an important factor influencing adsorption capacity. The specific surface area and pore volume of SLACM sample was evaluated by the BET method according to Nitrogen adsorption isotherms measured at $77 \mathrm{~K}$. The porous structure parameters of SLACM are shown in Table 1. It is clear from the table that the BET surface area of SLACM is $769.37 \mathrm{~m}^{2} / \mathrm{g}$ and the total pore volume is $0.47 \mathrm{~cm}^{3} / \mathrm{g}$. The chromium ions could be trapped in the pores of SLACM due to the radiuses of chromium ions were less than the pore size of the adsorbent [33]. The well-developed BET surface area and the total pore volume mean that the absorption performance of SLACM is good and it can be used as a substitute to conventional adsorbents. The average pore size of SLACM was found to be $2.46 \mathrm{~nm}$, and thus it belongs to the mesoporous materials.

Table 1. Porous structure parameters of SLACM.

\begin{tabular}{cccccc}
\hline Sample & $\mathrm{S}_{\text {BET }}\left(\mathrm{m}^{2} / \mathrm{g}\right)$ & $\mathrm{S}_{\text {mic }}\left(\mathrm{m}^{2} / \mathrm{g}\right)$ & $\mathrm{V}_{\text {tot }}\left(\mathrm{cm}^{3} / \mathrm{g}\right)$ & $\mathrm{V}_{\text {mic }}\left(\mathrm{cm}^{3} / \mathrm{g}\right)$ & $\mathrm{D}_{\mathrm{p}}(\mathrm{nm})$ \\
\hline SLACM & 769.37 & 639.28 & 0.47 & 0.26 & 2.46 \\
\hline
\end{tabular}

The surface microstructure and fracture micro appearance of SLACM was characterized using SEM and TEM, the surface microstructure of SLACM, fracture micro appearance of crushed SLACM before and after adsorption, the TEM images of SLACM before and after adsorption are presented in Figure 3. As shown in Figure 3a, the SLACM was a regular sphere and the diameter of most particles was around $0.5-1.5 \mathrm{~mm}$. Due to its larger size, the activated carbon can be separated out more easily from solution after adsorbing than the powdery SL. Thus, the recycling properties as well as convenience of use of the activated carbon were improved significantly. There were a lot of different size clearances and cracks present on the SLACM surface, as shown in Figure 3b, and these were the main channels through which the adsorbate could enter inside [10]. The well-developed pore structure should be responsible for the adsorption of $\mathrm{Cr}(\mathrm{VI})$ onto SLACM. It was also found by the fracture micro appearance of inner side of SLACM that the abundant pores and cavity structure confirmed the high specific surface areas of adsorbent, this could also be supported by the porous structure parameters of SLACM. The TEM image confirms that the SLACM before adsorption is hollow, and this observation is in line with SEM fracture surface image. As can be seen from Figure $3 \mathrm{~d}, \mathrm{f}$, the pores of SLACM were blocked, and obvious attachment appeared on the sample surface after $\mathrm{Cr}(\mathrm{VI})$ adsorption. The EDS spectrum of the SLACM before and after $\mathrm{Cr}(\mathrm{VI})$ adsorption and EDS elemental mapping patterns of C, N, O and Cr of SLACM after Cr(VI) adsorption were shown in Figure 4. It was observed that carbon, nitrogen and oxygen were the major elements in SLACM and that carbon, nitrogen, oxygen and chromium were the major elements on SLACM after $\mathrm{Cr}(\mathrm{VI})$ adsorption. The elements of nitrogen and oxygen have a greater promoting effect in the adsorption which could enhance the adsorption efficiency of SLACM for Cr(VI) [34]. The SLACM after adsorption showed distinct peaks of chromium 
present on the surface and the EDS mapping reveals that the chromium was evenly distributed over SLACM surface. Therefore, EDS analysis confirmed the adsorption of Cr(VI) onto SLACM.
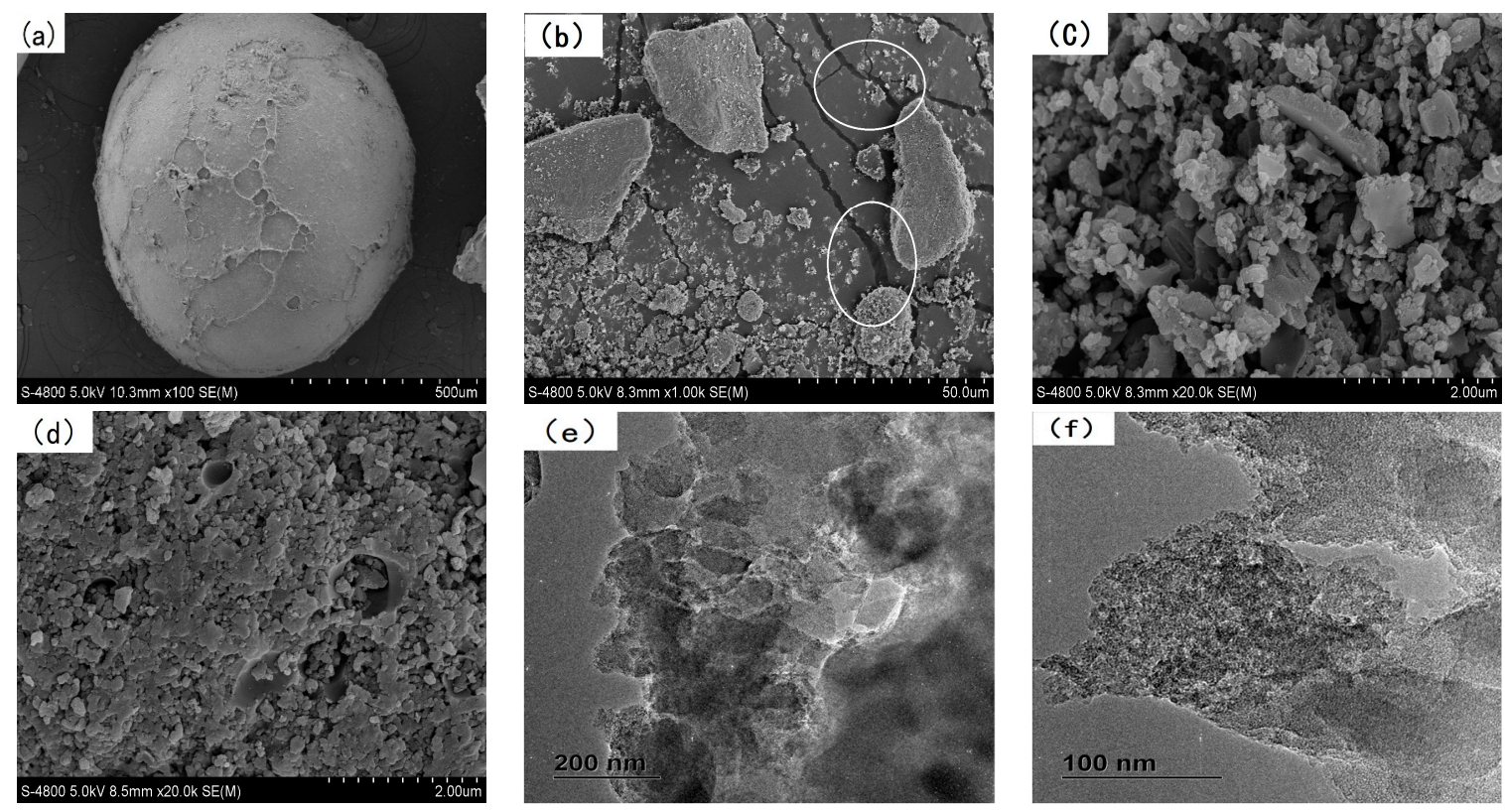

Figure 3. (a,b) SEM images of SLACM surface before $\mathrm{Cr}(\mathrm{VI})$ adsorption of 100 and 1 k; (c) SEM image of SLACM fracture surface before $\mathrm{Cr}(\mathrm{VI})$ adsorption of $20 \mathrm{k}$; (d) SEM image of SLACM fracture surface after $\mathrm{Cr}(\mathrm{VI})$ adsorption of $20 \mathrm{k}$; (e,f) TEM images of SLACM before and after Cr(VI) adsorption.
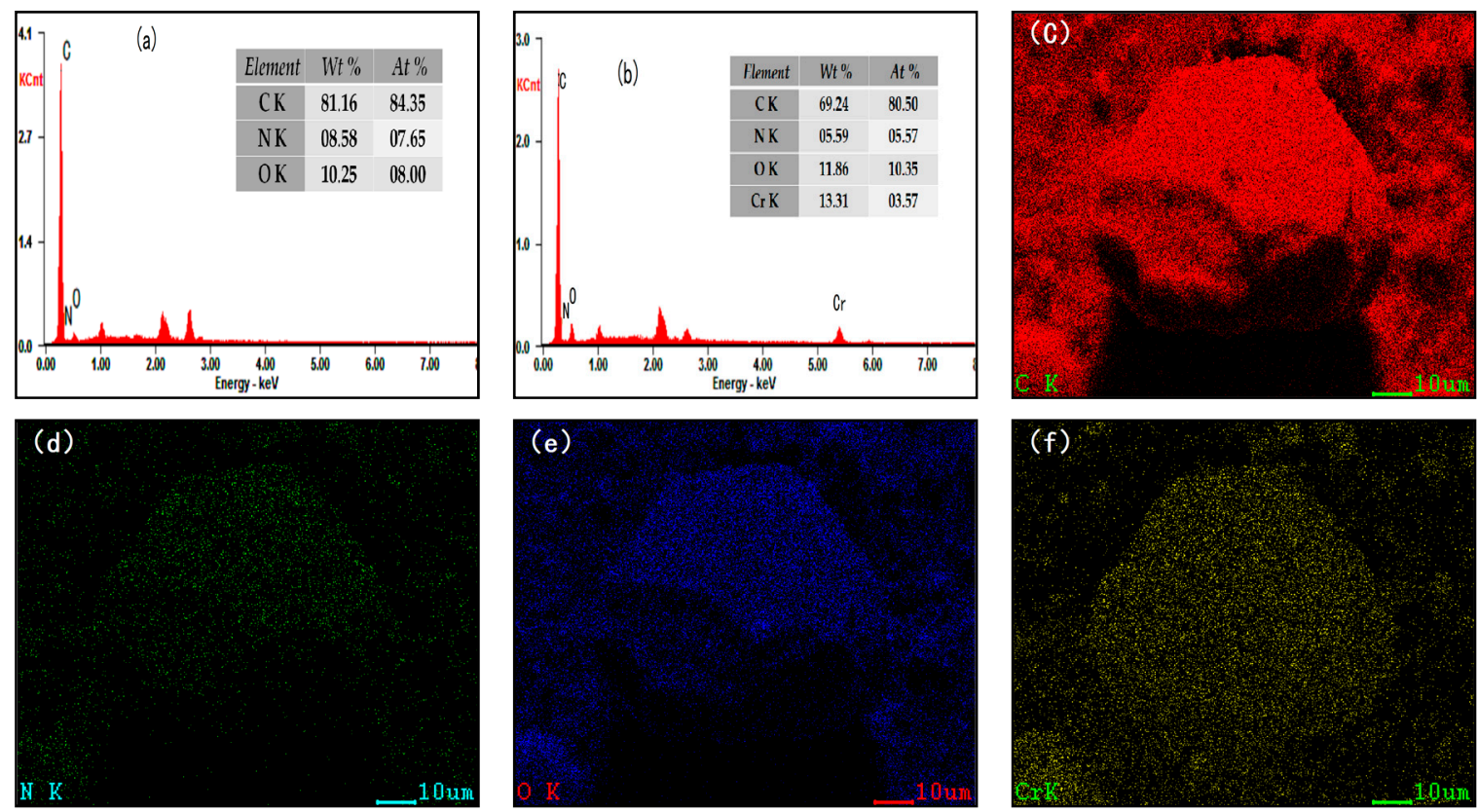

Figure 4. (a) EDS spectrum of SLACM before Cr(VI) adsorption; (b) EDS spectrum of SLACM after $\mathrm{Cr}(\mathrm{VI})$ adsorption; (c-f) EDS elemental mapping patterns of $\mathrm{C}, \mathrm{N}, \mathrm{O}$ and $\mathrm{Cr}$ after $\mathrm{Cr}(\mathrm{VI})$ adsorption.

The thermal behavior of the CMPS, ARM and PARM was analyzed under nitrogen atmosphere. The TG and derivative thermogravimetric (DTG) curves of SL, CMPS, ARM and PARM are illustrated in Figure 5. The SL has a high residual mass rate after heating and a low peak value of DTG than others. A high residual mass rate is positive for preparing of SLACM. Compared with CMPS, the maximum weight loss temperature $\left(T_{\max }\right)$ of AR was reduced more significantly. This is due to the destruction of part of long chain structure or aromatic substitution during the graft polymerization 
of SL and CMPS, the protection of lignin was break down [35]. For these reasons, the residual mass rate of ARM is much less than that of SL and CMPS. The residual mass rate of PARM has a larger increase compared to ARM, probably because of partial structural carbonization or pyrolysis in ARM during the oxidation process [36]. Keeping in mind the larger increase in the residual mass rate of PARM, it can be concluded that a higher yield SLACM can be prepared by using PARM as raw material compare to ARM. It is also clear from Figure 5 that the residual mass rate of all the samples did not decrease when the temperature was higher than $600{ }^{\circ} \mathrm{C}$, which suggests that the activation temperature should not be increased to higher than $600^{\circ} \mathrm{C}$ during the preparation of SLACM. Thus, the activation temperature for SLACM was found to be lower than activated carbon production from other studies in the literature [33,37-39], which can save a large amount of energy during production process.

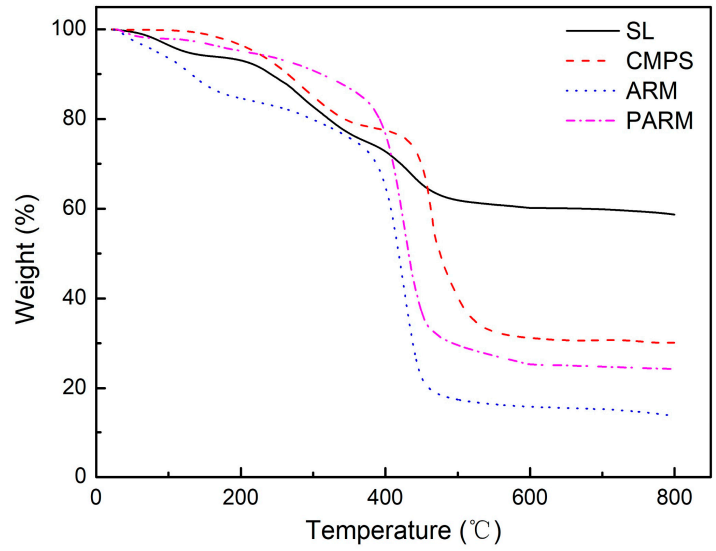

(a)

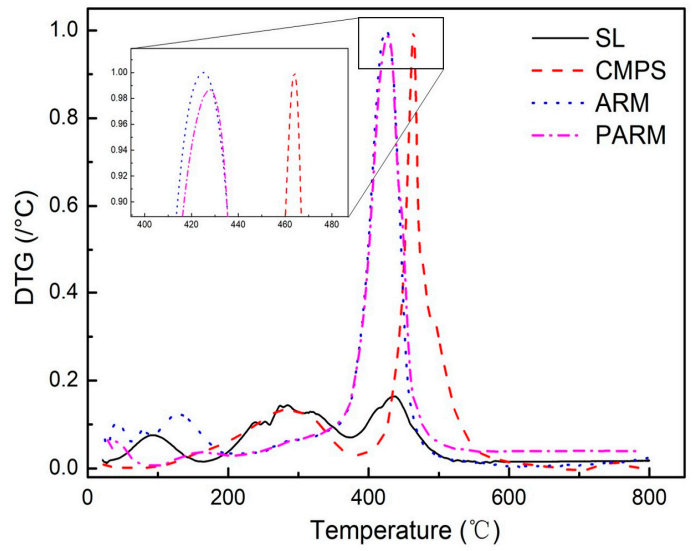

(b)

Figure 5. (a) The TG curves of SL, CMPS, ARM and PARM; (b) The DTG curves of SL, CMPS, ARM and PARM.

The structural variation of the SLACM samples and other materials were analyzed by FT-IR and the recorded spectra are shown in Figure 6a. The wide peak at $3423 \mathrm{~cm}^{-1}$ corresponding to stretching of aliphatic and phenolic - $\mathrm{OH}$ groups was observed in all of the samples, especially SL. The peaks at 1593 and $1444 \mathrm{~cm}^{-1}$ were typical of aromatic $\mathrm{C}-\mathrm{C}$ stretching and $\mathrm{C}-\mathrm{H}$ bending in SL. The peak intensity of SL at 3423 and $1593 \mathrm{~cm}^{-1}$ was much stronger than ARM, which meant aromatic phenolic -OH groups in SL were combined with aminated CMPS after Mannich reaction. After the pre-oxidation, new peaks appeared in PARM. The peak around $2929 \mathrm{~cm}^{-1}$ was attributed to the stretching vibration of saturated hydrocarbon $-\mathrm{CH}_{3},-\mathrm{CH}_{2}$ - and the methyl or methylene in aliphatic groups. The peak at $1660 \mathrm{~cm}^{-1}$ was attributed to the stretching vibration of amide $-\mathrm{CO}-\mathrm{N}$ [31]. This may be because the $-\mathrm{NH}$ oxidizes in AR and reaction produced -CO-N groups. The peak at $1103 \mathrm{~cm}^{-1}$ was attributed to the antisymmetric stretching vibration of $\mathrm{S}-\mathrm{O}$ in $\mathrm{SO}^{3-}$ groups, and the $\mathrm{SO}^{3-}$ group was from SL [32]. This indicates that SL was successfully grafted onto aminated CMPS. After activation, the peak amount of SLACM was significantly less than PARM and the peak intensity was obviously weaker than PARM. This was because some chemical bonds of PARM were broken down at higher temperature, such as alken- $\mathrm{CH}_{3}$, aliphatic ether - $\mathrm{C}-\mathrm{O}-$, and the benzene ring replacing op $(\mathrm{CH})$, and forming graphitized carbon materials [31]. Some small weak peaks appeared at 3423 and $1593 \mathrm{~cm}^{-1}$ on the SLACM curve. These results show that SLACM contains a variety of functional groups including phenols, alcohols, alkenes, amines, etc. The main functional groups are in good agreement with biomass-activated carbon from others [31,40]. The oxygen-containing functional groups of SLACM determine the surface acidity-basicity and the adsorption performances. After adsorption of $\mathrm{Cr}(\mathrm{VI})$, these peaks of SLACM-Cr were not obvious, indicating an interaction between the $\mathrm{Cr}$ (VI) and SLACM. 


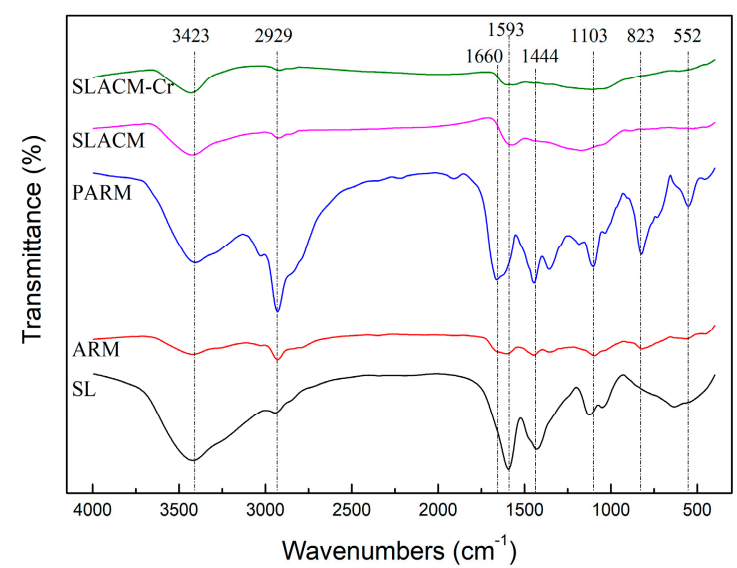

(a)

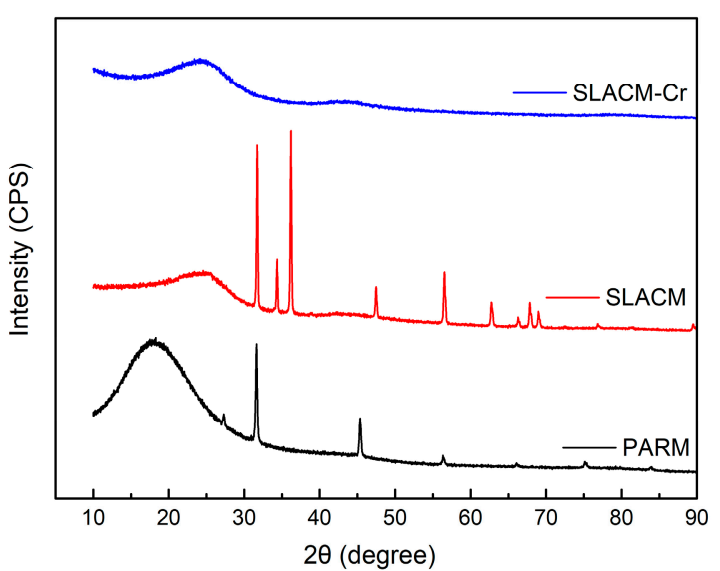

(b)

Figure 6. (a) The FT-IR spectra of samples; (b) The XRD curves of samples.

The XRD spectra representing the crystalline structures of PARM, SLACM, SLACM-Cr (after adsorption of $\mathrm{Cr}(\mathrm{VI})$ ) are shown in Figure $6 \mathrm{~b}$. The results show that PARM has an amorphous wide peak at $18.28^{\circ}$. The wide peak of the SLACM decreased and moved to the right compared to PARM. This illustrates that the distance of crystal face of SLACM decreased and the graphitization degree increased after activation at high temperature [33,41]. The diffraction peaks of SLACM occurred at $31.72^{\circ}, 34.35^{\circ}$, $36.2^{\circ}, 56.54^{\circ}$. This is because the crystal structure of samples changed at higher temperature, main performance for small particle graphite structure and undefined structure. The diffraction peaks of SLACM-Cr disappeared after the $\mathrm{Cr}(\mathrm{VI})$ adsorption. This was due to fact that the $\mathrm{Cr}(\mathrm{VI})$ was adsorbed successfully by SLACM as a physical or chemical form and the adsorbate $\mathrm{Cr}(\mathrm{VI})$ damaged the crystal structures.

\subsection{Effect of Initial $p H$ on Adsorption}

The initial $\mathrm{pH}$ of the solution is an important parameter that influences the adsorption capacity of the adsorbent for metal ions [42]. The effect of initial $\mathrm{pH}$ on the adsorption capacity of SLACM for $\mathrm{Cr}(\mathrm{VI})$ was tested, and the results are shown in Figure 7a. It is clear from the results that adsorption capacity of SLACM for $\mathrm{Cr}(\mathrm{VI})$ is strongly dependent on the initial $\mathrm{pH}$ of the solution. Moreover, the adsorption capacity of SLACM continuously decreases as the $\mathrm{pH}$ increases from 2.0 to 9.0. This result is comparable with other consequences reported in the literature [43]. $\mathrm{Cr}(\mathrm{VI})$ exist in the form of oxyanions in solution, and the existence form of $\mathrm{Cr}(\mathrm{VI})$ ion depends mainly on the solution $\mathrm{pH}$ value. The predominant $\mathrm{Cr}(\mathrm{VI})$ existence forms are dichromate $\left(\mathrm{Cr}_{2} \mathrm{O}_{7}{ }^{2-}\right)$ and hydrogen chromate $\left(\mathrm{HcrO}^{4-}\right)$ when the $\mathrm{pH}$ of the aqueous solutions was in range of 2.0-6.0. When the $\mathrm{pH}$ exceeded 7.0, chromate $\left(\mathrm{CrO}_{4}{ }^{2-}\right)$ was the main $\mathrm{Cr}(\mathrm{VI})$ species [33,37]. The initial $\mathrm{pH}$ of the solution simultaneously affects the adsorbent surface charge and degree of ionization [44]. At lower $\mathrm{pH}$, the functional groups on the surface of the SLACM were protonated by plentiful hydrogen ions, and there was a strong electrostatic interaction between the negatively charged $\mathrm{Cr}(\mathrm{VI})$ and the positively charged SLACM. The strong electrostatic interaction was very favorable for adsorbing dichromate and hydrogen chromate. $\mathrm{Cr}(\mathrm{VI})$ could be reduced to $\mathrm{Cr}(\mathrm{III})$ with the SLACM surface charge provided by the oxygen-containing functional groups, such as -C-O- and - $\mathrm{OH}$. The $\mathrm{Cr}(\mathrm{VI})$ was adsorbed by complexation or reduced may be described by the following reactions (Equations (3)-(6)) [13,33]. The adsorbed $\mathrm{Cr}(\mathrm{VI})$ was reduced to $\mathrm{Cr}(\mathrm{III})$ by the electron-donor groups of the porous carbon from corn straw was also proved by Ma et al. [33]. Therefore, the highest adsorption capacity of SLACM for $\mathrm{Cr}(\mathrm{VI})$ was the $75.25 \mathrm{mg} / \mathrm{g}$ when the initial $\mathrm{pH}$ of solution was 2.0. As the initial $\mathrm{pH}$ of the solution increased, the protonation degree of the SLACM surface functional groups decreased and gradually converted to negatively charged. There exists competitive adsorption between $\mathrm{OH}$ - and chromate, which interferes with the binding site on the adsorbents; the $\mathrm{OH}$ - content in solution increased, and the competitive adsorption was 
found to be stronger at higher $\mathrm{pH}$ values. Electrostatic repulsion and competitive adsorption caused a decrease in the adsorption capacity of SLACM for $\mathrm{Cr}(\mathrm{VI})$; therefore, the adsorption capacity of SLACM for $\mathrm{Cr}(\mathrm{VI})$ dropped to $19.42 \mathrm{mg} / \mathrm{g}$ when the $\mathrm{pH}$ was raised to 9.0. Moreover, $\mathrm{Cr}(\mathrm{VI})$ and the $-\mathrm{COOH}$ group of SLACM may have an ion exchange reaction (Equation (7)). These results indicate that the $\mathrm{Cr}(\mathrm{VI})$ removal behavior was affected by the initial $\mathrm{pH}$ of solution, and $\mathrm{pH} 2.0$ was applied to the following adsorption experiments to obtain the optimal adsorption performance in this study.

$$
\begin{gathered}
\mathrm{RO}^{-}+\mathrm{Cr}^{6+} \rightarrow \mathrm{RO}^{-} \ldots \mathrm{Cr}^{6+} \\
3 \mathrm{ROH}+\mathrm{Cr}_{2} \mathrm{O}_{7}^{2-}+4 \mathrm{H}^{+} \rightarrow 3 \mathrm{RO}+\mathrm{HCrO}_{4}^{-}+\mathrm{Cr}^{3+}+3 \mathrm{H}_{2} \mathrm{O} \\
3 \mathrm{ROH}+\mathrm{HCrO}_{4}^{-}+4 \mathrm{H}^{+} \rightarrow 3 \mathrm{RO}+\mathrm{Cr}^{3+}+4 \mathrm{H}_{2} \mathrm{O} \\
3 \mathrm{C}-\mathrm{O}-+3 \mathrm{HCrO}_{4}^{-}+5 \mathrm{H}^{+} \rightarrow 3 \mathrm{C}-\mathrm{O}+3 \mathrm{R} \ldots \mathrm{Cr}^{3+}+4 \mathrm{H}_{2} \mathrm{O} \\
3 \mathrm{R}-\mathrm{COOH}+\mathrm{Cr}^{6+} \rightarrow \mathrm{R}-\mathrm{COO}^{-} \ldots \mathrm{Cr}^{6+}+\mathrm{H}^{+}
\end{gathered}
$$

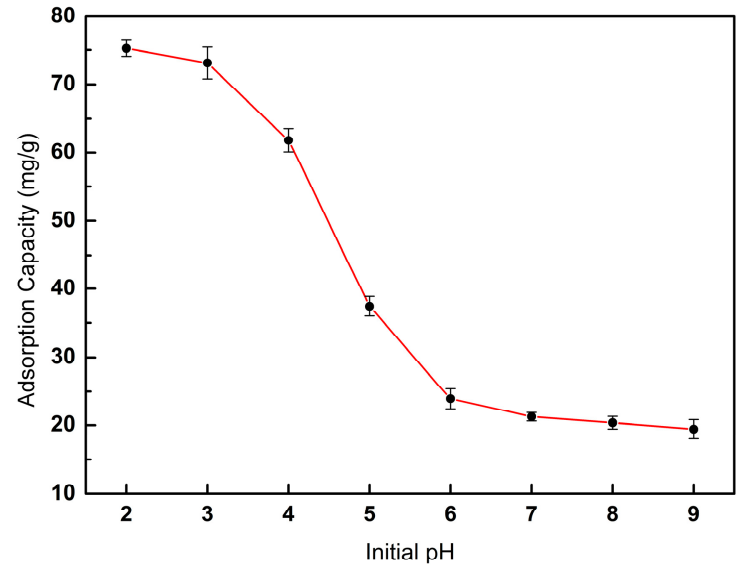

(a)

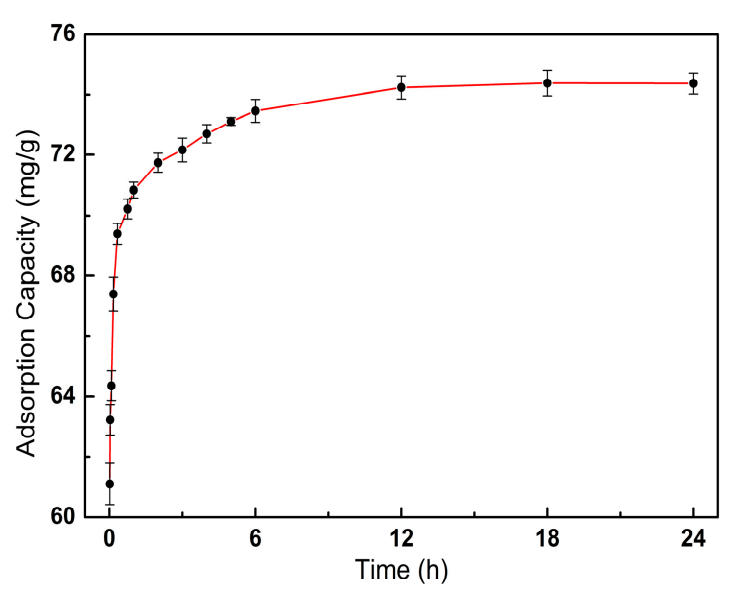

(b)

Figure 7. (a) Effect of initial pH on adsorption capacity of SLACM for $\mathrm{Cr}(\mathrm{VI})$; (b) Effect of time on adsorption capacity of SLACM for Cr(VI).

\subsection{Adsorption Kinetics}

To evaluate the kinetic behavior of adsorption process of SLACM for $\mathrm{Cr}(\mathrm{VI})$, the adsorption time of SLACM in solution was set as $2 \mathrm{~min}$ to $24 \mathrm{~h}$. The adsorption velocity of SLACM for Cr(VI) was different at different time points during the adsorption process, but eventually it all balanced out. The adsorption kinetics were determined in order to study the relationship between the adsorption capacity and adsorption time during the adsorption process, and were significant in explaining the adsorption process in view of the order of the rate constants. The relationship of adsorption capacity of SLACM for $\mathrm{Cr}(\mathrm{VI})$ and adsorption time are shown in Figure $7 \mathrm{~b}$. As can be seen, the adsorption capacity of SLACM for Cr(VI) increased rapidly in the first hour and was $70.84 \mathrm{mg} / \mathrm{g}$ after $1 \mathrm{~h}$. The increase in adsorption capacity slowed down between 1 and $6 \mathrm{~h}$, and then the adsorption capacity gradually reached equilibrium. The equilibrium adsorption capacity was $74.38 \mathrm{mg} / \mathrm{g}$. The pseudo first-order (PFO), pseudo second-order (PSO) and Elovich models were applied to the experimental data to evaluate the adsorption kinetics, in order to understand the controlling mechanisms of the $\mathrm{Cr}(\mathrm{VI})$ sorption on SLACM $[7,27]$. These models are given as the following equations, respectively.

$$
\begin{gathered}
\text { PFO : } q_{t}=q_{e}\left(1-e^{-k_{1} t}\right), \\
\text { PSO : } q_{t}=\frac{q_{e}^{2} k_{2} t}{1+q_{e} k_{2} t},
\end{gathered}
$$




$$
\text { Elovich : } q_{t}=\frac{1}{\beta} \ln (1+\alpha \beta t),
$$

where $q_{t}(\mathrm{mg} / \mathrm{g})$ is the adsorption capacity at $\mathrm{t}$ time, $q_{e}(\mathrm{mg} / \mathrm{g})$ is the adsorption capacity at $\mathrm{t}$ time at equilibrium, $t(\mathrm{~h})$ is adsorption capacity time, $k_{1}\left(\mathrm{~min}^{-1}\right)$ is the PFO equilibrium rate constant, $k_{2}$ $(\mathrm{g} / \mathrm{mg} \cdot \mathrm{min})$ is the PSO equilibrium rate constant, $\alpha$ and $\beta$ are Elovich constants. The adsorption kinetic constants and dynamic fitting parameters were summarized in Table 2. The fitted results in Table 2 show that the Elovich model is in better agreement with the experimental results when explaining adsorption rate than the PFO and PSO models, indicating the better suitability of Elovich model for describing the adsorption kinetics of $\mathrm{Cr}(\mathrm{VI})$ onto SLACM. Therefore, the adsorption type of $\mathrm{Cr}(\mathrm{VI})$ onto SLACM was determined to be predominantly chemisorption, which was consistent with heavy metal ion adsorption results using different solid adsorbents, as described in other literature studies [7]. The adsorption of SLACM includes mass transfer of $\mathrm{Cr}(\mathrm{VI})$ to the external and internal surface of adsorbent, particle diffusion, active site adsorption of adsorbent and other multi-stages adsorption process [40]. The adsorption process can be divided into several stages. $\mathrm{The} \mathrm{Cr}(\mathrm{VI})$ in solution firstly diffused to the SLACM surface then it entered inside the adsorbent through pores. The adsorbate was adsorbed by pore structures and the active sites on external and internal surface of SLACM during these processes. The available active sites on the surface was sufficient and the pore structure was not completely filled during the initial stages of adsorption process, the mass transfer resistance of $\mathrm{Cr}(\mathrm{VI})$ was small. This was due to the presence of a greater driving force provided by the higher initial concentration of $\mathrm{Cr}(\mathrm{VI})$, which increased the probability of collisions between $\mathrm{Cr}(\mathrm{VI})$ and the active sites. Therefore, the adsorption process has a high adsorption rate at the beginning. The active sites on the surface were inhibited and the pore structure was filled gradually through the process of adsorption. Therefore, the interactions between $\mathrm{Cr}(\mathrm{VI})$ and active sites decreased and the mass transfer resistance of adsorbate increased. As shown in the curve in Figure $7 \mathrm{~b}$, the adsorption rate decreased and the adsorption capacity of SLACM for $\mathrm{Cr}(\mathrm{VI})$ gradually reached to the equilibrium state.

Table 2. Adsorption kinetics model parameters of SLACM for $\mathrm{Cr}(\mathrm{VI})$.

\begin{tabular}{ccc}
\hline Model & Parameters & Value \\
\hline \multirow{3}{*}{ PFO } & $q_{e}$ & 71.1 \\
& $K_{L}$ & 106.75 \\
& $R^{2}$ & 38.83 \\
\hline \multirow{2}{*}{ PSO } & $q_{e}$ & 72.03 \\
& $K_{2}$ & 3.59 \\
& $R^{2}$ & 73.12 \\
\hline \multirow{2}{*}{ Elovich } & $\alpha$ & 5.81 \\
& $\beta$ & 0.54 \\
& $R^{2}$ & 95.63 \\
\hline
\end{tabular}

\subsection{Adsorption Isotherm}

SLACM was brought into contact with different concentrations of the solution (50-600 mg/L) in order to evaluate the effect of initial concentration on the adsorption capacity of SLACM for Cr(VI). Adsorption isotherms were used to evaluate the adsorption type and study the adsorption behavior under different equilibrium condition. The Langmuir model and Freundlich model were used to fit equilibrium experimental data of $\mathrm{Cr}(\mathrm{VI})$ adsorption on SLACM at temperatures of 20, 30 and $40^{\circ} \mathrm{C}$ [37]. The isotherm models can be explained as follows.

This is an example of an equation:

$$
\text { Langmuir : } q_{e}=\frac{K_{L} C_{e} q_{m}}{1+K_{L} C_{e}}
$$




$$
\begin{gathered}
R_{L}=\frac{1}{1+K_{L} C_{0}}, \\
\text { Freundlich : } q_{e}=K_{F} C_{e}^{\frac{1}{n}},
\end{gathered}
$$

where $q_{e}(\mathrm{mg} / \mathrm{g})$ is the maximum adsorption capacity, $C_{e}(\mathrm{mg} / \mathrm{L})$ is the equilibrium $\mathrm{Cr}(\mathrm{VI})$ concentration, $q_{m}(\mathrm{mg} / \mathrm{g})$ is monolayer adsorption capacity, $K_{L}(\mathrm{~L} / \mathrm{mg})$ is the Langmuir affinity constant, $K_{F}(\mathrm{~L} / \mathrm{mg})$ is the Freundlich constant related to the adsorption capacity of the adsorbent and $n$ is an empirical constant related to the adsorption intensity which varies with the heterogeneity of material.

The experimental data and non-linear fitting curves are shown in Figure 8. The fitting results and correlation coefficients are shown in Table 3. The Langmuir isotherm model is generally applicable to monolayer adsorption onto a homogeneous surface with a finite number of identical and equivalent sites. Meanwhile, it was supposed that the interaction forces between different adsorbates, between adsorbed molecules and adsorbent surface-active sites does not exist. The Freundlich isotherm model is generally applied to multilayer adsorption with interaction forces between different adsorbates, between adsorbed molecules and adsorbent surface-active sites [7]. As can be seen from the results in Table 3, Langmuir adsorption model has a higher correlation coefficient, and it can be better fitted to the adsorption type of SLACM for Cr(VI) than Freundlich model. Therefore, the isotherm model fitting results indicate that the adsorption process of SLACM for $\mathrm{Cr}(\mathrm{VI})$ was monolayer adsorption. The separation factor $\left(R_{L}\right)$ is an important parameter for Langmuir isotherm model, which can be used to evaluate whether the adsorption process is favorable $\left(0<R_{L}<1\right)$, linear $\left(R_{L}=1\right)$, or unfavorable $\left(R_{L}>1\right)$ [37]. In this test $\mathrm{Cr}(\mathrm{VI})$ concentration range (50-600 mg/L), the $R_{L}$ values decreased from 0.1 to 0.0092 at $20^{\circ} \mathrm{C}$, from 0.0833 to 0.0075 at $30^{\circ} \mathrm{C}$, and from 0.0588 to 0.0052 at $40{ }^{\circ} \mathrm{C}$. All of the $R_{L}$ values were greater than 0 but less than 1 , and which were decreases with higher $\mathrm{Cr}(\mathrm{VI})$ initial concentration and higher adsorption temperature. The results indicate that the adsorption process of $\mathrm{Cr}(\mathrm{VI})$ onto SLACM was favorable in the concentration range studied, the higher $\mathrm{Cr}(\mathrm{VI})$ initial concentration and higher temperature was beneficial for adsorption. The equilibrium data fitted well with the Langmuir isotherm models, and the maximum adsorption capacity of $\mathrm{Cr}(\mathrm{VI})$ on SLACM was around $227.7 \mathrm{mg} / \mathrm{g}$ initial $\mathrm{pH} 2,40{ }^{\circ} \mathrm{C}$. The $\mathrm{Cr}(\mathrm{VI})$ adsorption capacities of the other adsorbents from biomass waste are listed in Table 4 . within comparison with others, it can be seen that the SLACM had excellent adsorption capacity for the $\mathrm{Cr}(\mathrm{VI})$ removal from aqueous solution, and thus it could be a promising adsorbent.

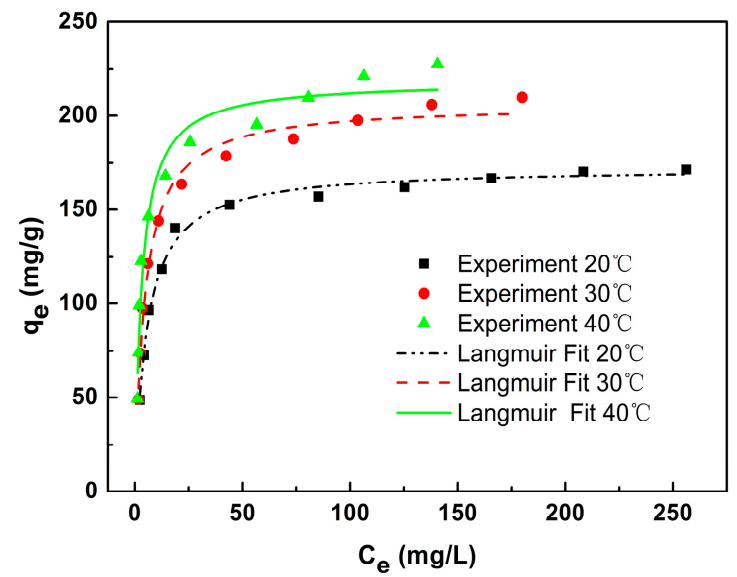

(a)

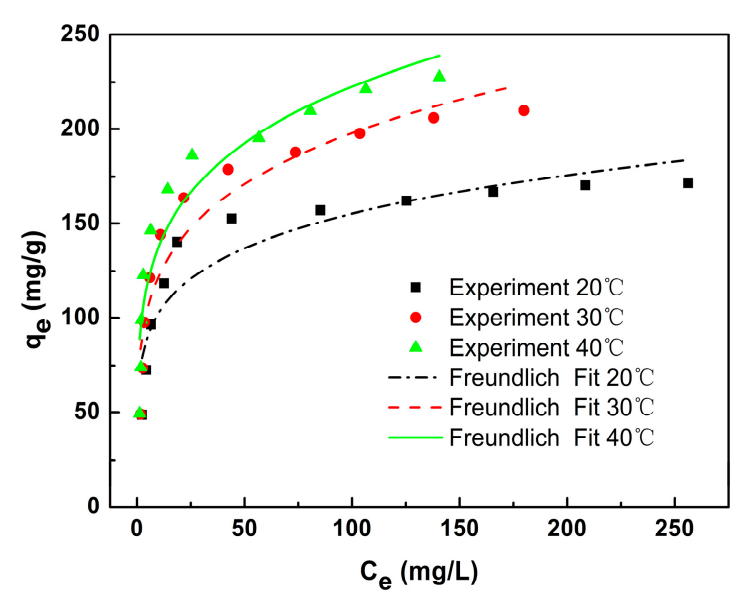

(b)

Figure 8. (a) Adsorption isotherm of $\mathrm{Cr}(\mathrm{VI})$ onto SLACM and Langmuir isotherm models fitting curves; (b) Adsorption isotherm of $\mathrm{Cr}(\mathrm{VI})$ onto SLACM and Freundlich isotherm models fitting curves. 
Table 3. Adsorption isotherm parameters and correlation coefficients of SLACM for Cr(VI).

\begin{tabular}{ccccccc}
\hline \multirow{2}{*}{ Temp ${ }^{\circ} \mathbf{C}$} & \multicolumn{3}{c}{ Langmuir } & \multicolumn{3}{c}{ Freundlich } \\
\cline { 2 - 6 } & $\boldsymbol{q}_{\boldsymbol{m}} \mathbf{m g} / \mathbf{g}$ & $\boldsymbol{K}_{\boldsymbol{L}} \mathbf{~} \mathbf{m} \mathbf{m g}$ & $\boldsymbol{R}^{2}$ & $\boldsymbol{K}_{\boldsymbol{F}} \mathbf{L} / \mathbf{m g}$ & $\frac{1}{n} \mathbf{~ L / m g}$ & $\boldsymbol{R}^{2}$ \\
\hline 20 & 172.41 & 0.18 & 99.22 & 67.80 & 0.18 & 84.45 \\
30 & 206.13 & 0.22 & 98.59 & 75.09 & 0.21 & 89.59 \\
40 & 218.19 & 0.32 & 96.27 & 85.05 & 0.21 & 89.03 \\
\hline
\end{tabular}

Table 4. The $\mathrm{Cr}(\mathrm{VI})$ adsorption capacities of the other adsorbents from biomass waste. Data from $[33,34,39,44,45]$.

\begin{tabular}{cccccc}
\hline Adsorbent Precursor & Activating Agend & $\boldsymbol{q}_{\mathbf{m a x}}(\mathbf{m g} / \mathbf{g})$ & $\mathbf{p H}$ & Temp ${ }^{\circ} \mathbf{C}$ & Reference \\
\hline Mixed waste tea & $/$ & 94.34 & 2.0 & 30 & {$[44]$} \\
Coffee ground & $/$ & 87.72 & 2.0 & 30 & {$[44]$} \\
Algal bloom & $\mathrm{CO}_{2}$ & 96 & 1.0 & 20 & {$[39]$} \\
Glucose & $\mathrm{KOH}$ & 332.53 & 2.0 & 25 & {$[45]$} \\
Corn straw & $\mathrm{KOH}$ & 175.44 & 3.0 & 25 & {$[33]$} \\
Glucose monohydrate & $\mathrm{H}_{2} \mathrm{O}$ & 117.2 & 2.0 & 30 & {$[34]$} \\
SL & $\mathrm{ZnCl}_{2}$ & 227.7 & 2.0 & 40 & This work \\
\hline
\end{tabular}

\section{Conclusions}

Activated carbon microsphere was prepared from powdered SL without adding any kind of binder. The preparation process consisted of activated carbon precursor preparation by Mannich reaction and $\mathrm{ZnCl}_{2}$ activation. The results of the study indicated that the SLACM had excellent adsorption capacity for the removal of $\mathrm{Cr}(\mathrm{VI})$ from aqueous solution. It was found that the SL had a good Mannich reaction with aminated CMPS in creating ARM, and the ARM with good thermal stability was beneficial to the SLACM preparation. SLACM comprises tiny spherical particles with a well-developed porous structure. As a mesoporous material, the surface area and average pore size of spherical SLACM with a porous structure are $769.37 \mathrm{~m}^{2} / \mathrm{g}$ and $2.46 \mathrm{~nm}$, respectively. The adsorption capacity of SLACM for $\mathrm{Cr}(\mathrm{VI})$ is greatly dependent on solution $\mathrm{pH}$, and the acidity of the solution is beneficial to $\mathrm{Cr}(\mathrm{VI})$ adsorption. The adsorption kinetic results showed that the adsorption of SLACM for Cr(VI) mainly occurred during the initial stages of the adsorption process; the Elovich model was in better agreement with the experimental data to describe adsorption process than the PFO and PSO models. In the range of test temperatures, the adsorption capacity increased with increasing temperature. The equilibrium data fitted well with the Langmuir isotherm models, and the maximum adsorption capacity of $\mathrm{Cr}(\mathrm{VI})$ on SLACM was around $227.7 \mathrm{mg} / \mathrm{g}$ at an initial $\mathrm{pH}$ value of 2 and a temperature of $40{ }^{\circ} \mathrm{C}$. Therefore, the SL could be considered to be a potential raw material for the production of activated carbon in removing the $\mathrm{Cr}(\mathrm{VI})$ from wastewater. The SLACM prepared in this work provides the possibility of wastewater treatment in the future.

Author Contributions: Conceptualization, K.Y. and J.C.; methodology, K.Y. and J.X.; formal analysis, K.Y. and P.X.; investigation, K.Y. and J.X.; resources, J.C.; writing-original draft preparation, K.Y. and J.X.; writing-review and editing, K.Y., Q.Z. and K.M.U.; project administration, J.C.; funding acquisition, J.C. All authors have read and agreed to the published version of the manuscript.

Funding: This research was funded by National Key R\&D Program of China, grant number 2017YFD0601004.

Conflicts of Interest: The authors declare no conflict of interest.

\section{References}

1. Sessarego, S.; Rodrigues, S.C.G.; Xiao, Y.; Lu, Q.; Hill, J.M. Phosphonium-enhanced chitosan for Cr(VI) adsorption in wastewater treatment. Carbohydr. Polym. 2019, 211, 249-256. [CrossRef] 
2. Vilela, P.B.; Dalalibera, A.; Duminelli, E.C.; Becegato, V.A.; Paulino, A.T. Adsorption and removal of chromium (VI) contained in aqueous solutions using a chitosan-based hydrogel. Environ. Sci. Pollut. Res. 2018, 26, 28481-28489. [CrossRef] [PubMed]

3. Hussein, H.; Ibrahim, S.F.; Kandeel, K.; Moawad, H. Biosorption of heavy metals from waste water using Pseudomonas sp. Electron. J. Biotechnol. 2004, 7, 38-46. [CrossRef]

4. Yang, J.; Yu, M.; Chen, W. Adsorption of hexavalent chromium from aqueous solution by activated carbon prepared from longan seed: Kinetics, equilibrium and thermodynamics. J. Ind. Eng. Chem. 2015, 21, 414-422. [CrossRef]

5. Fazlzadeh, M.; Rahmani, K.; Zarei, A.; Abdoallahzadeh, H.; Nasiri, F.; Khosravi, R. A novel green synthesis of zero valent iron nanoparticles (NZVI) using three plant extracts and their efficient application for removal of $\mathrm{Cr}(\mathrm{VI})$ from aqueous solutions. Adv. Powder Technol. 2017, 28, 122-130. [CrossRef]

6. Miretzky, P.; Cirelli, A.F. Cr(VI) and Cr(III) removal from aqueous solution by raw and modified lignocellulosic materials: A review. J. Hazard. Mater. 2010, 180, 1-19. [CrossRef]

7. Norouzi, S.; Heidari, M.; Alipour, V.; Rahmanian, O.; Fazlzadeh, M.; Mohammadi-moghadam, F.; Nourmoradi, H.; Goudarzi, B.; Dindarloo, K. Preparation, characterization and Cr(VI) adsorption evaluation of $\mathrm{NaOH}$-activated carbon produced from Date Press Cake; an agro-industrial waste. Bioresour. Technol. 2018, 258, 48-56. [CrossRef]

8. Tan, X.; Liu, S.; Liu, Y.; Gu, Y.; Zeng, G.; Hu, X.; Wang, X.; Liu, S.; Jiang, L. Biochar as potential sustainable precursors for activated carbon production: Multiple applications in environmental protection and energy storage. Bioresour. Technol. 2017, 227, 359-372. [CrossRef]

9. Tripathi, A.; Rawat Ranjan, M. Heavy Metal Removal from Wastewater Using Low Cost Adsorbents. J. Bioremediat. Biodegrad. 2015, 6, 1-5. [CrossRef]

10. Ilangovan, M.; Guna, V.; Olivera, S.; Ravi, A.; Muralidhara, H.B.; Santosh, M.S.; Reddy, N. Highly porous carbon from a natural cellulose fiber as high efficiency sorbent for lead in waste water. Bioresour. Technol. 2017, 245, 296-299. [CrossRef]

11. Qiang, W.; Jiaoyan, S.; Mengzhu, S. Characteristic of adsorption, desorption and oxidation of Cr (III) on birnessite. Energy Procedia 2011, 5, 1104-1108. [CrossRef]

12. Parlayici, Ş.; Pehlivan, E. Comparative study of $\mathrm{Cr}(\mathrm{VI})$ removal by bio-waste adsorbents: Equilibrium, kinetics, and thermodynamic. J. Anal. Sci. Technol. 2019, 10, 15. [CrossRef]

13. Zhang, J.; Chen, S.; Zhang, H.; Wang, X. Removal behaviors and mechanisms of hexavalent chromium from aqueous solution by cephalosporin residue and derived chars. Bioresour. Technol. 2017, 238, 484-491. [CrossRef] [PubMed]

14. Zhang, L.; Mu, C.; Zhong, L.; Xue, J.; Zhou, Y.; Han, X. Recycling of Cr (VI) from weak alkaline aqueous media using a chitosan/triethanolamine/Cu (II) composite adsorbent. Carbohydr. Polym. 2019, 205, 151-158. [CrossRef]

15. Garg, V.K.; Gupta, R.; Kumar, R.; Gupta, R.K. Adsorption of chromium from aqueous solution on treated sawdust. Bioresour. Technol. 2004, 92,79-81. [CrossRef]

16. Aghababaei, A.; Ncibi, M.C.; Sillanpää, M. Optimized removal of oxytetracycline and cadmium from contaminated waters using chemically-activated and pyrolyzed biochars from forest and wood-processing residues. Bioresour. Technol. 2017, 239, 28-36. [CrossRef]

17. Hernandez-Ramirez, O.; Holmes, S.M. Novel and modified materials for wastewater treatment applications. J. Mater. Chem. 2008, 18, 2751. [CrossRef]

18. Pham, T.D.; Tran, T.T.; Le, V.A.; Pham, T.T.; Dao, T.H.; Le, T.S. Adsorption characteristics of molecular oxytetracycline onto alumina particles: The role of surface modification with an anionic surfactant. J. Mol. Liq. 2019, 287, 110900. [CrossRef]

19. Pham, T.; Bui, T.; Nguyen, V.; Bui, T.; Tran, T.; Phan, Q.; Pham, T.; Hoang, T. Adsorption of Polyelectrolyte onto Nanosilica Synthesized from Rice Husk: Characteristics, Mechanisms, and Application for Antibiotic Removal. Polymers 2018, 10, 220. [CrossRef]

20. Pham, T.D.; Do, T.T.; Ha, V.L.; Doan, T.H.Y.; Nguyen, T.A.H.; Mai, T.D.; Kobayashi, M.; Adachi, Y. Adsorptive removal of ammonium ion from aqueous solution using surfactant-modified alumina. Environ. Chem. 2017, 14, 327. [CrossRef]

21. Qi, W.; Zhao, Y.; Zheng, X.; Ji, M.; Zhang, Z. Adsorption behavior and mechanism of Cr(VI) using Sakura waste from aqueous solution. Appl. Surf. Sci. 2016, 360, 470-476. [CrossRef] 
22. Kazakis, N.; Kantiranis, N.; Kalaitzidou, K.; Kaprara, E.; Mitrakas, M.; Frei, R.; Vargemezis, G.; Vogiatzis, D.; Zouboulis, A.; Filippidis, A. Environmentally available hexavalent chromium in soils and sediments impacted by dispersed fly ash in Sarigkiol basin (Northern Greece). Environ. Pollut. 2018, 235, 632-641. [CrossRef] [PubMed]

23. Rangabhashiyam, S.; Balasubramanian, P. The potential of lignocellulosic biomass precursors for biochar production: Performance, mechanism and wastewater application-A review. Ind. Crop. Prod. 2019, 128, 405-423.

24. Li, W.; Zhang, L.; Peng, J.; Li, N.; Zhu, X. Preparation of high surface area activated carbons from tobacco stems with $\mathrm{K} 2 \mathrm{CO} 3$ activation using microwave radiation. Ind. Crop. Prod. 2008, 27, 341-347. [CrossRef]

25. Gao, H.; Liu, Y.; Zeng, G.; Xu, W.; Li, T.; Xia, W. Characterization of $\mathrm{Cr}(\mathrm{VI})$ removal from aqueous solutions by a surplus agricultural waste-Rice straw. J. Hazard. Mater. 2008, 150, 446-452. [CrossRef]

26. Mekonnen, E.; Yitbarek, M.; Soreta, T.R. Kinetic and thermodynamic studies of the adsorption of Cr(VI) onto some selected local adsorbents. South Afr. J. Chem. 2015, 68, 45-52. [CrossRef]

27. Malwade, K.; Lataye, D.; Mhaisalkar, V.; Kurwadkar, S.; Ramirez, D. Adsorption of hexavalent chromium onto activated carbon derived from Leucaena leucocephala waste sawdust: Kinetics, equilibrium and thermodynamics. Int. J. Environ. Sci. Technol. 2016, 13, 2107-2116. [CrossRef]

28. Rangabhashiyam, S.; Selvaraju, N. Adsorptive remediation of hexavalent chromium from synthetic wastewater by a natural and $\mathrm{ZnCl}_{2}$ activated Sterculia guttata shell. J. Mol. Liq. 2015, 207, 39-49. [CrossRef]

29. Doherty, W.O.S.; Mousavioun, P.; Fellows, C.M. Value-adding to cellulosic ethanol: Lignin polymers. Ind. Crop. Prod. 2011, 33, 259-276. [CrossRef]

30. Xi, Y.; Yang, D.; Qiu, X.; Wang, H.; Huang, J.; Li, Q. Renewable lignin-based carbon with a remarkable electrochemical performance from potassium compound activation. Ind. Crop. Prod. 2018, 124, 747-754. [CrossRef]

31. Zhang, N.; Shen, Y. One-step pyrolysis of lignin and polyvinyl chloride for synthesis of porous carbon and its application for toluene sorption. Bioresour. Technol. 2019, 284, 325-332. [CrossRef]

32. Geng, J.; Gu, F.; Chang, J. Fabrication of magnetic lignosulfonate using ultrasonic-assisted in situ synthesis for efficient removal of $\mathrm{Cr}(\mathrm{VI})$ and Rhodamine B from wastewater. J. Hazard. Mater. 2019, 375, 174-181. [CrossRef]

33. Ma, H.; Yang, J.; Gao, X.; Liu, Z.; Liu, X.; Xu, Z. Removal of chromium (VI) from water by porous carbon derived from corn straw: Influencing factors, regeneration and mechanism. J. Hazard. Mater. 2019, 369, 550-560. [CrossRef]

34. Kumar, S.; Sivaranjanee, R.; Saravanan, A. Carbon sphere: Synthesis, characterization and elimination of toxic $\mathrm{Cr}(\mathrm{VI})$ ions from aquatic system. J. Ind. Eng. Chem. 2018, 60, 307-320.

35. Fang, W.; Weisheng, N.; Andong, Z.; Weiming, Y. Enhanced anaerobic digestion of corn stover by thermo-chemical pretreatment. Int. J. Agric. Biol. Eng. 2015, 8, 84-90.

36. Wang, F.; Zhang, D.; Wu, H.; Yi, W.; Fu, P.; Li, Y.; Li, Z. Enhancing biogas production of corn stover by fast pyrolysis pretreatment. Bioresour. Technol. 2016, 218, 731-736. [CrossRef]

37. Xu, Z.; Yuan, Z.; Zhang, D.; Huang, Y.; Chen, W.; Sun, Z.; Zhou, Y. Cr(VI) removal with rapid and superior performance utilizing cost-efficient waste-polyester-textile-based mesoporous carbon: Behavior and mechanism. J. Mol. Liq. 2019, 278, 496-504. [CrossRef]

38. Martins, A.C.; Pezoti, O.; Cazetta, A.L.; Bedin, K.C.; Yamazaki, D.A.S.; Bandoch, G.F.G.; Asefa, T.; Visentainer, J.V.; Almeida, V.C. Removal of tetracycline by NaOH-activated carbon produced from macadamia nut shells: Kinetic and equilibrium studies. Chem. Eng. J. 2015, 260, 291-299. [CrossRef]

39. Cui, Y.; Masud, A.; Aich, N.; Atkinson, J.D. Phenol and Cr(VI) removal using materials derived from harmful algal bloom biomass: Characterization and performance assessment for a biosorbent, a porous carbon, and Fe/C composites. J. Hazard. Mater. 2019, 368, 477-486. [CrossRef]

40. Pezoti, O.; Cazetta, A.L.; Bedin, K.C.; Souza, L.S.; Martins, A.C.; Silva, T.L.; Santos Júnior, O.O.; Visentainer, J.V.; Almeida, V.C. NaOH-activated carbon of high surface area produced from guava seeds as a high-efficiency adsorbent for amoxicillin removal: Kinetic, isotherm and thermodynamic studies. Chem. Eng. J. 2016, 288, 778-788. [CrossRef]

41. Mondal, S.; Derebe, A.T.; Wang, K. Surface functionalized carbon microspheres for the recovery of copper ion from refinery wastewater. Korean J. Chem. Eng. 2018, 35, 147-152. [CrossRef] 
42. Jeon, C. Removal of $\mathrm{Cr}(\mathrm{VI})$ from aqueous solution using amine-impregnated crab shells in the batch process. J. Ind. Eng. Chem. 2019, 77, 111-117. [CrossRef]

43. Zhang, X.; Lv, L.; Qin, Y.; Xu, M.; Jia, X.; Chen, Z. Removal of aqueous Cr(VI) by a magnetic biochar derived from Melia azedarach wood. Bioresour. Technol. 2018, 256, 1-10. [CrossRef]

44. Cherdchoo, W.; Nithettham, S.; Charoenpanich, J. Removal of $\mathrm{Cr}(\mathrm{VI})$ from synthetic wastewater by adsorption onto coffee ground and mixed waste tea. Chemosphere 2019, 221, 758-767. [CrossRef]

45. Liang, H.; Song, B.; Peng, P.; Jiao, G.; Yan, X.; She, D. Preparation of three-dimensional honeycomb carbon materials and their adsorption of Cr(VI). Chem. Eng. J. 2019, 367, 9-16. [CrossRef]

(C) 2020 by the authors. Licensee MDPI, Basel, Switzerland. This article is an open access article distributed under the terms and conditions of the Creative Commons Attribution (CC BY) license (http://creativecommons.org/licenses/by/4.0/). 